\title{
Polyamide 6 single polymer composites
}

\author{
D. Bhattacharyya*, P. Maitrot, S. Fakirov \\ Centre for Advanced Composite Materials, Department of Mechanical Engineering, The University of Auckland, Private \\ Bag 92019, Auckland, New Zealand
}

Received 8 January 2009; accepted in revised form 4 June 2009

\begin{abstract}
Combining the two basic techniques used for the preparation of single polymer composites (SPCs), hot compaction and film stacking, a polyamide 6 (PA 6) single polymer composite was manufactured. The starting materials were PA 6 high tenacity yarn (reinforcement) and PA 6 film prepared via melt quenching (matrix), both expected to be the two principal polymorphic modifications of PA 6 and thus differing in their melting temperatures. The prepared single polymer composite is characterized by a layered structure and shows superior mechanical properties due to the good wetting - tensile modulus is improved by $200 \%$ and the ultimate tensile strength - by $300-400 \%$ as compared to the isotropic matrix film. Improvement of the interfacial adhesion via transreactions promoted by $\mathrm{Sb}_{2} \mathrm{O}_{3}$ as a catalyst was also undertaken.
\end{abstract}

Keywords: polymer composites, single polymer composites, polyamide 6, mechanical properties

\section{Introduction}

The environmental impact of the steadily increasing use of plastic materials requires the development of new combinations of materials, possibly with improved properties but with reduced environmental harm. The creation of single polymer composites (SPCs) seems to be an alternative in this respect because they do not contain mineral fillers and are characterized by improved adhesion quality between the matrix and the reinforcement.

Formulated for the first time by Capiati and Porter [1], this type of material was further developed by Ward and his group [2-8] including patenting and commercialization of the 'hot compaction' technique [2]. This method used an assembly of highly oriented polymer fibers or tapes subjected to heating to a critical temperature, while being held together under pressure such that a thin volume of material on the surface of each oriented element is 'selectively melted' creating a matrix [9]. The uniqueness of the hot compaction technique is the use of one constituent only.

In contrast to the foregoing approach, the most frequently used technique is film stacking where the film is generally chosen to have a lower melting temperature $\left(T_{m}\right)$ compared to the orientated fibers [10-16]. A characteristic feature of this technique [10-19] is that the two constituents of the same polymer are used as starting materials for manufacturing of SPCs. Recently, the authors have explored both of these approaches for preparation of SPCs based on poly(ethylene terephthalate) (PET) using a new type of reinforcement, namely, PET nanofibrils, by means of techniques developed earlier [20, 21] for nanofibrillar composites (NFCs). In the case of two-constituent SPCs, layers of PET nanofibrils with diameters between 50 and $150 \mathrm{~nm}$ were sandwiched between PET film with lower $T_{m}$ and thereafter compression moulded [22]. The improvements in both, the tensile modulus $(E)$ and the 
ultimate tensile strength $\left(\sigma_{u t s}\right)$ were around $65 \%$ and for some specimens up to $100 \%$, thus approaching the improvement values of the PET SPCs prepared by Hine and Ward [6] by means of the hot compaction method.

The same nanofibrils were used for the preparation of nanofibrillar SPCs applying the one-constituent approach and the improvements of $E, \sigma_{u t s}$ and yield strength were all around 300\% [23]. One specimen even showed the maximum modulus value of 10.6 GPa, which was very close to that of PET/ glass fibre (60/40 wt \%) composites reaching a modulus of around $11 \mathrm{GPa}$ [6].

In addition to these studies with nanofibrils, the twoconstituent approach was applied to polyamide 66 (PA 66) for the manufacture of SPCs using it as the matrix and as the reinforcement with rather different melting temperatures. They were thought to be the two well known polymorphic modifications of PA 66 [24]. In the present paper, the same study is extended to polyamide 6 (PA 6), where again an attempt was made to use the extremely high ability of formation of polymorphic crystalline modifications [25]. For example, PA 6 quenched from its melt, crystallizes in the $\gamma$-modification, while at higher temperatures and/or during drawing it undergoes crystallization in the $\alpha$-modification with the higher-melting temperature. This polymorphic transition takes place in such a smooth way that the existence of the $\gamma$-modification cannot be detected during the heating in the differential scanning calorimeter. Only after applying a chemical cross-linking in the amorphous areas before scanning Fakirov and Avramova [26] succeeded to prevent the recrystallization process and thus determined the equilibrium melting temperature $\left(T_{m}^{0}\right)$ of the $\gamma$-modification of PA 6 amounting to $T_{m}^{0}=$ $208^{\circ} \mathrm{C}$ (against $T_{m}^{0}=278^{\circ} \mathrm{C}$ of the $\alpha$-modification) [26].

An additional reason for performing this study is the fact that, to the best of the authors' knowledge, there has been no report on single polymer composites based on PA 6.

\section{Experimental details}

\subsection{Materials and sample preparation}

PA 6 commercial type 2650 from Hoechst, Germany, in the form of pellets was used as the matrix.
Commercial UV stabilized high tenacity PA 6 yarn of the code 222 and, according to Firestone, Nashville, Tennessee, USA, of 1848 dtex and 136 filaments played the role of reinforcement. In order to get reinforcement with a higher $T_{m}$, the yarn was subjected to annealing in vacuum for $3 \mathrm{~h}$ at $150^{\circ} \mathrm{C}$. The matrix was prepared in the form of a thin film (thickness of $150 \mu \mathrm{m}$ ) by means of compression moulding at $260^{\circ} \mathrm{C}$ for $5 \mathrm{~min}$ and at a pressure of about $35 \mathrm{MPa}$ followed by quenching in ice water together with the covering of Teflon films. Another film was prepared using slow cooling to room temperature. The reinforcing yarn of continuous filaments was wound onto a metal plate using a lathe. Each of the two yarn layers was sandwiched between two matrix films and subjected to compression molding at $200^{\circ} \mathrm{C}$ for $5 \mathrm{~min}$ under a pressure of $\sim 15 \mathrm{MPa}$. The pressure was maintained during cooling to room temperature. In this way composite films with an average thickness of $\sim 500 \mu \mathrm{m}$ were prepared. All the materials used were dried in a vacuum oven at $80^{\circ} \mathrm{C}$ for $24 \mathrm{~h}$ before being subjected to any thermal treatment.

$\mathrm{Sb}_{2} \mathrm{O}_{3}$ as a catalyst for transreactions was supplied by Sigma Aldrich and used in its 'as supplied' form. For this purpose filaments were coated with the powder-like material amounting to $1-2 \mathrm{wt} \%$ of the composite.

\subsection{Methods of characterisation}

The melting temperature values and the melting intervals, which were of particular importance in this study, along with the degree of crystallinity $\left(w_{c}(\mathrm{DSC})\right)$ were determined using a differential scanning calorimeter (DSC) of type DSC Q 1000 of TA Instruments. Typically 6 to $8 \mathrm{mg}$ of material was subjected to scanning at a heating rate of $10^{\circ} \mathrm{C} / \mathrm{min}$. The $w_{c}$ (DSC) was calculated by the Equation (1):

$w_{c}(\mathrm{DSC})=\frac{\Delta H_{\mathrm{exp}}}{\Delta H^{0}}$

where $\Delta H_{\exp }$ and $\Delta H^{0}$ are the experimentally measured and the ideal (for 100\% crystalline sample) values of the heat of fusion, respectively. For $\Delta H^{0}$ the value of $204.0 \mathrm{~J} / \mathrm{g}$ [27] was used. Scanning electron microscope (SEM) observations were performed on a Philips XL30S instrument with an 
acceleration voltage of $5 \mathrm{kV}$. Images were taken from the fracture surfaces of the composite samples following the mechanical testing.

The mechanical performance of the starting isotropic films of PA 6 (matrix) and the prepared SPC was evaluated in tensile mode using an Instron 5567 machine equipped with a load cell interface, model $\mathrm{SN}-1000 \mathrm{~N}$, gauge length of $50 \mathrm{~mm}$ and cross-head speed of $5 \mathrm{~mm} / \mathrm{min}$ at a temperature of $20{ }^{\circ} \mathrm{C}$ and $50 \%$ humidity. The testing was performed after room conditioning of the samples for two weeks since the absorbed moisture $(2.2 \%$ as an equilibrium amount) had a dramatic effect on the mechanical properties as demonstrated by Hine and Ward for PA 66 [3]. The testing was performed according to ASTM D882 on $15 \mathrm{~mm}$ wide strips, punched by means of a die from the compression moulded films. The results of five specimens were averaged for each sample.

It is important to note that the calculation of the cross-sectional area of the reinforcing filaments via their textile characteristics seemed to be less reliable than the use of microscopes for the same purpose. In addition, because of the unusual thermal behaviour of the samples, the DSC measurements were repeated with newly prepared samples, which were also mechanically tested immediately. In this way, a second series of samples was prepared using as a matrix PA 6 film subjected to slow cooling after compression molding and thus hoping to get a more realistic idea about the reinforcing effect. Since this series of sample was tested mechanically on the same day, it was denoted as ' 1 day' in contrast to the first series denoted as ' 14 days'. In both cases the annealed PA 6 yarn was used as reinforcement.

\section{Results and discussion}

While dealing with single polymer composites an issue of particular importance is the selection of the proper temperature for the thermal treatment leading up to the consolidation of the reinforcing elements without melting them completely. For example, a successful hot compaction of PET textile filaments was performed by Hine and Ward [6] only within $2^{\circ} \mathrm{C}$ of the $T_{m}$ of the respective PET sample. In this way, various approaches have been used for the preparation of constructs with as differ- ent as possible $T_{m}$ when the two-constituent approach has been used.

Following the experience of Karger-Kocsis and coworkers on polypropylene [14-16] as well as authors' recent work on PA 66 [24], in the present study it is attempted to prepare PA 6 film with $T_{m}$ as low as possible using the fact that quenched PA 6 melt crystallises predominantly in the lower melting $\gamma$-modification $[25,26]$. This film is used later as the matrix in the SPCs prepared afterwards. The role of the reinforcement is played by the high tenacity PA 6 commercial yarn. In order to enhance the subsequent processing an attempt was undertaken to increase the yarn's melting temperature via annealing. The thermal behaviour of the starting materials and the final SPC was tested by DSC measurements - the results are displayed in Figure 1. Surprisingly, all the samples studied show

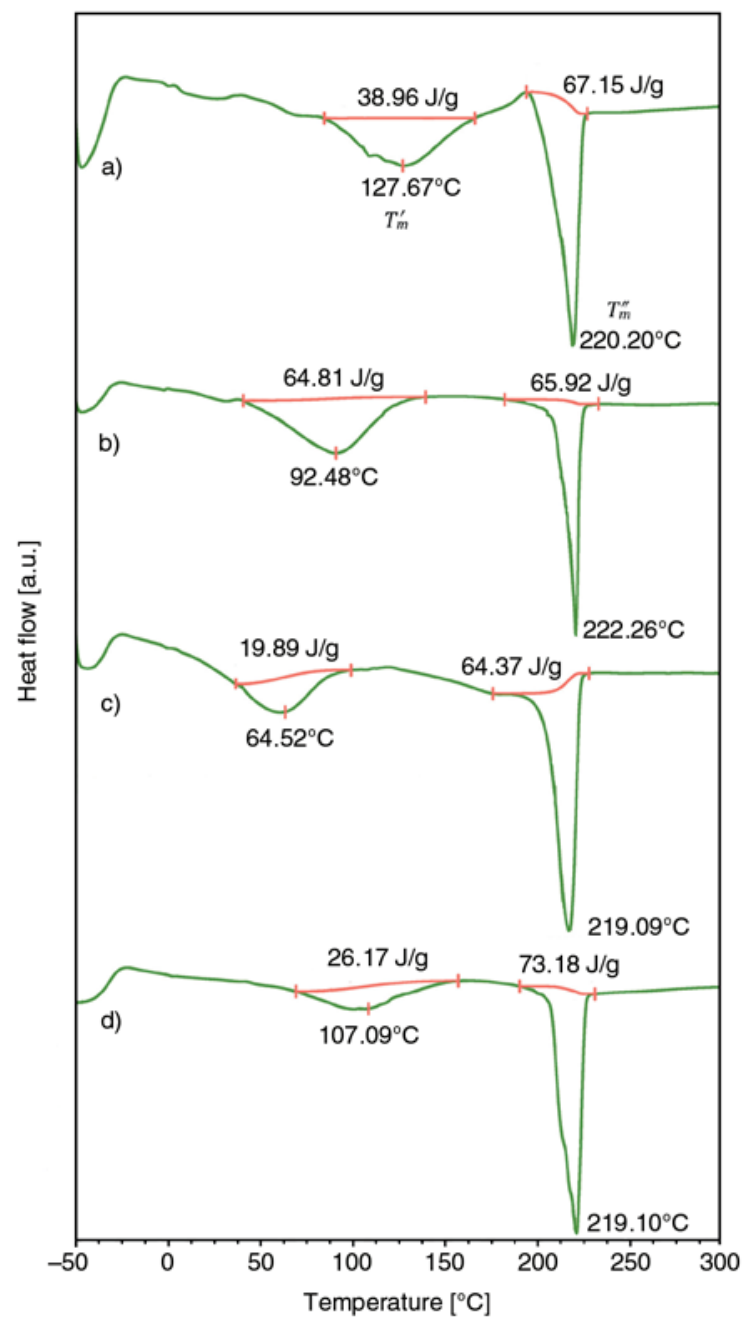

Figure 1. DSC traces of: a) PA 6 film (matrix), b) PA 6 yarn (reinforcement), c) PA 6 yarn (reinforcement) after annealing at $150^{\circ} \mathrm{C}$ for $360 \mathrm{~min}$ in a vacuum, d) PA 6-SPC 
two melting peaks, a lower one $\left(T_{m}^{\prime}\right)$ in vicinity of $100^{\circ} \mathrm{C}$ and a higher one $\left(T_{m}^{\prime \prime}\right)$ at $220^{\circ} \mathrm{C}$.

The observation that the highly drawn PA 6 displays also the presence of a lower-melting modification, Figure $1 \mathrm{~b}$, which is still present after annealing of the yarn at $150^{\circ} \mathrm{C}$ is rather unusual. Even more surprising is the result that the same fraction melts at a lower temperature after annealing $\left(T_{m}^{\prime}=64.5^{\circ} \mathrm{C}\right.$ instead of $92.5^{\circ} \mathrm{C}$ for the case without annealing, Figures $1 \mathrm{c}$ and $1 \mathrm{~b}$, respectively). At the same time, the amount of this lower melting fraction decreases threefold after annealing, see Figure 1. Regardless of the nature of this lower melting fraction, its presence in the two starting materials, the film and the yarn, is very favourable for composite processing since its early melting contributes to the good adhesion quality between the matrix and reinforcement.

It is quite evident that such a thermal behaviour is not a typical one for a neat homopolymer. One of the possible explanation for this observation is that the samples subjected to DSC analysis do not represent a neat homopolymer, but a polymer blend. Many companies are using this approach for getting uncommon for the respective homopolymer properties. Just for polyamides it is known that the company EMS, Germany, blends various polyamides, thus demonstrating unusual for the neat polyamide properties.

The clarification for this uncommon thermal behaviour could be a subject of an independent study as such a task is beyond the frame of this study because the melting parameters of the respective matrix and reinforcement were of interest only for selecting the proper processing temperatures. The latter has to be in such a range, where a complete melting of the reinforcement is excluded. As far as the matrix is concerned, there is no such limitation - the further the melting progresses, the better is the result. From this point of view, the 'unusual' thermal behaviour of the matrix and reinforcement, regardless of the reasons for such a behaviour, seems to be very favourable for manufacturing of single polymer composites, what is the main task of this study.

It is to be noted that as the relevant analysis (X-ray scattering) is missing, statements regarding polymorphic modifications might be hypothesis. However, notwithstanding this lack of evidence, the primary parameter of this study is the melting temperature.

The final PA 6-based SPC also demonstrates a two melting-peak phenomenon, Figure 1d, where the first one shows the same crystallinity as that of the annealed yarn $(\sim 10 \%)$, while the second peak is characterised by the highest degree of crystallinity $\left(w_{c}=36 \%\right)$, Table 1 .

SEM images of the PA 6 yarns, which have been used as reinforcement are shown in Figure 2a, whereas the cross-sections of the final PA 6 single polymer composite at progressing magnifications are depicted in Figures $2 b-2 d$. It is evident that the textile filaments are very homogeneous with respect to their diameters being around $50 \mu \mathrm{m}$, Figure $2 \mathrm{a}$. The composite film clearly demonstrates a layered structure comprised of two outer film layers and a layer in-between of the uniaxially aligned yarn filaments. What is particularly important for

Table 1. Thermal (DSC) data (first peak of melting $T_{m}^{\prime}$, second peak of melting, $T_{m}^{\prime \prime}$, and degree of crystallinity, $\left(w_{c}\right)$ as well as mechanical test data (tensile modulus, $E$, and ultimate tensile strength, $\sigma_{u t s}$ ) of the PA 6 matrix, PA 6 yarn reinforcement, PA 6 single polymer composite (PA 6-SPC) with and without catalyst, all averaged from 5 specimens

\begin{tabular}{|c|c|c|c|c|c|c|c|c|c|}
\hline \multirow{3}{*}{ No } & \multirow{3}{*}{ Material } & \multirow{2}{*}{\multicolumn{2}{|c|}{$\begin{array}{l}\text { Thermal data } \\
{\left[{ }^{\circ} \mathbf{C}\right]}\end{array}$}} & \multirow{2}{*}{\multicolumn{2}{|c|}{$\begin{array}{c}\mathbf{w}_{\mathbf{c}} \\
{[\%]}\end{array}$}} & \multicolumn{4}{|c|}{ Mechanical data } \\
\hline & & & & & & \multicolumn{2}{|c|}{ E [GPa] } & \multicolumn{2}{|c|}{$\sigma_{\text {uts }}[\mathrm{MPa}]$} \\
\hline & & $\mathbf{T}_{\mathbf{m}}^{\prime}$ & $\mathbf{T}_{\mathbf{m}}^{\prime \prime}$ & $\mathbf{w}^{\prime}$ & $\mathbf{w}_{\mathbf{c}}^{\prime \prime}$ & 14 days & 1 day & 14 days & 1 day \\
\hline 1 & $\begin{array}{l}\text { PA } 6 \text { film } \\
\text { (matrix) }\end{array}$ & 127.67 & 220.20 & 19.10 & 32.92 & $0.86 \pm 0.3$ & $1.5 \pm 0.07$ & $24.63 \pm 2.4$ & $47.75 \pm 3.1$ \\
\hline 2 & $\begin{array}{l}\text { PA } 6 \text { yarn } \\
\text { (reinforcement) }\end{array}$ & 92.48 & 222.26 & 31.77 & 32.31 & $3.29 \pm 0.2$ & - & $760.8 \pm 41.5$ & - \\
\hline 4 & $\begin{array}{l}\text { PA 6-SPC } \\
\text { (without catalyst) }\end{array}$ & 107.09 & 219.10 & 12.83 & 35.87 & $2.75 \pm 0.2$ & $4.04 \pm 0.05$ & $102 \pm 20.4$ & $271.52 \pm 42.4$ \\
\hline 5 & $\begin{array}{l}\text { Improvement of PA 6-SPC } \\
\text { (without catalyst) [\%] }\end{array}$ & - & - & - & - & 220 & 169 & 314 & 470 \\
\hline 6 & $\begin{array}{l}\text { PA 6-SPC } \\
\text { (with catalyst) }\end{array}$ & - & - & - & - & $2.97 \pm 0.51$ & $5.31 \pm 0.1$ & $122.3 \pm 14.4$ & $359.07 \pm 77.3$ \\
\hline 7 & $\begin{array}{l}\text { Improvement of PA 6-SPC } \\
\text { (with catalyst) [\%] }\end{array}$ & - & - & - & - & 245 & 254 & 395 & 650 \\
\hline
\end{tabular}



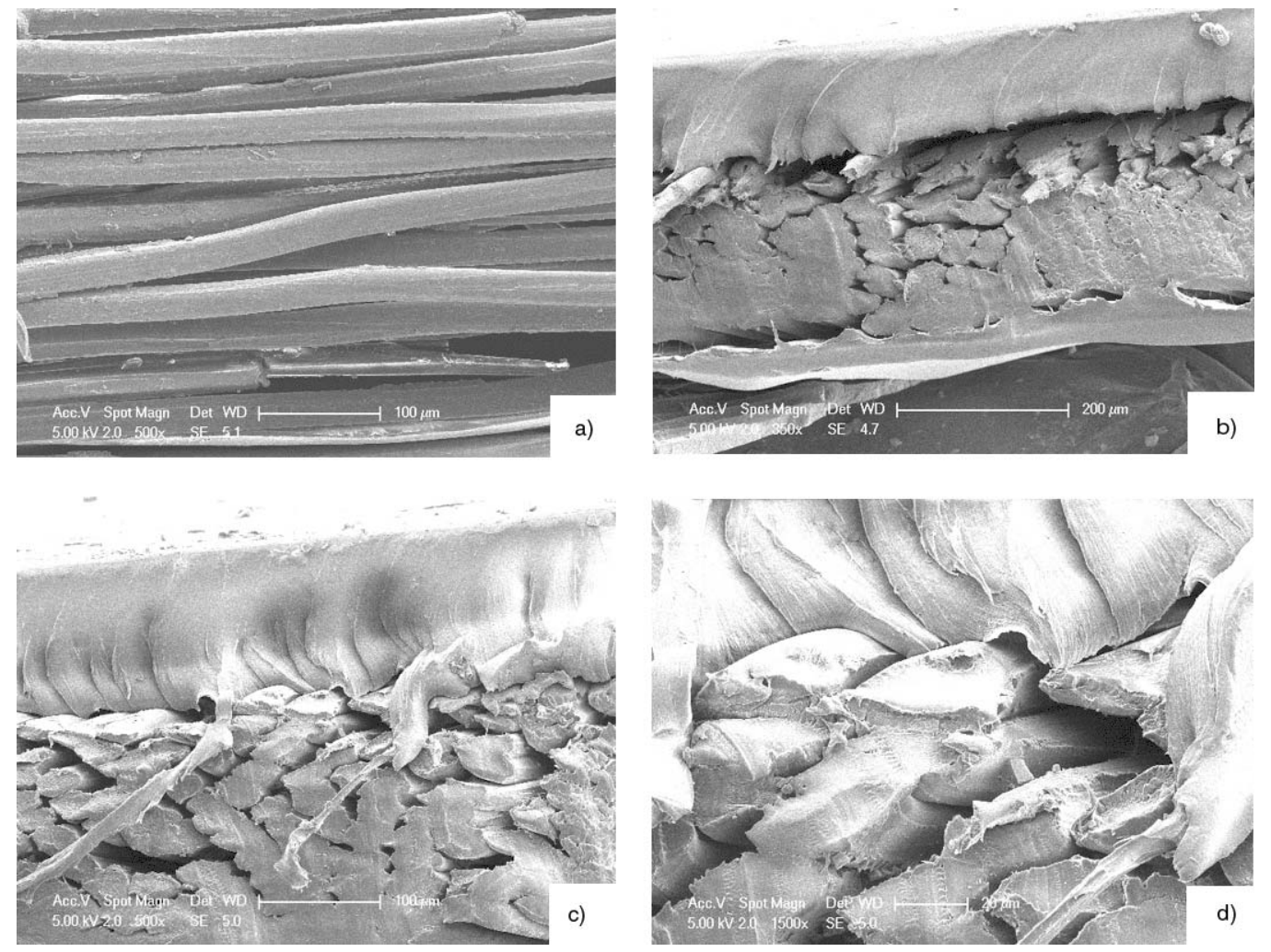

Figure 2. SEM micrographs of: a) PA 6 yarn (reinforcement), b)-d) cross section of PA 6-SPC at increasing magnifications

this reinforcing layer is the fact that during the hot pressing at the selected temperature, the fiber surfaces were melted resulting in the traditional hot compaction. Obviously, this process was enhanced by the fact that even in the highly drawn PA 6 material crystalline species with very low melting temperature $\left(T_{m}^{\prime}=92.5^{\circ} \mathrm{C}\right.$ and $T_{m}^{\prime}=64.5^{\circ} \mathrm{C}$ after annealing, Figures $1 \mathrm{~b}$ and $1 \mathrm{c}$, respectively) were present.

The matrix film of the SPC preserved its homogeneity and did not penetrate into the filaments. In fact, in the present case one deals with a layered structure of the composite material as a result of the combination of the two processes, hot compaction and film stacking, Figures 2b-2d. As demonstrated by Hine et al. [9], such a combination of film stacking with hot compaction gives a better overall balance of mechanical properties and a wider temperature range for processing, compared to a standard hot compaction procedure without a film. Another advantage of this combination is the better wetting of the reinforcement compared to the traditional film stacking process, due to the partial melting of all the fiber surfaces [9]. The fact that the used PA 6 comprises a low-melting crystalline fraction $\left(T_{m}^{\prime}=127.6^{\circ} \mathrm{C}\right.$, Figure $1 \mathrm{a}$, amounting to $30 \%$ of the film mass, Table 1) also contributed in the same direction. The same holds for the reinforcing fibers (Figures $1 \mathrm{~b}$ and 1c, Table 1). These low-melting crystalline fractions of the two constituents ensure good compaction and wetting between the composite elements during the hot pressing.

Stress-strain curves of the starting materials, the PA 6 film and the yarn as well as those of the final SPC are shown in Figure 3. The SPC samples were prepared in the presence or absence of a catalyst enhancing the transreactions. Results for the two series of samples, the dry (1 day) and wet (14 days) are given; the enlarged portions of the stress-strain curves used for the evaluation of the $E$ modulus are also shown.

The reason for the experiments with a catalyst may be attributed to the well known fact that the condensation polymers (polyesters, polyamides, etc) undergo additional condensation and transreactions, also called exchange reactions if the appropriate conditions (temperature, vacuum, duration, catalyst) are available [28]. Since the processing temperature used for manufacturing of SPCs coincides with the temperature interval typical for the occurrence of transreactions, it would seem appealing to explore this opportunity for the creation of 


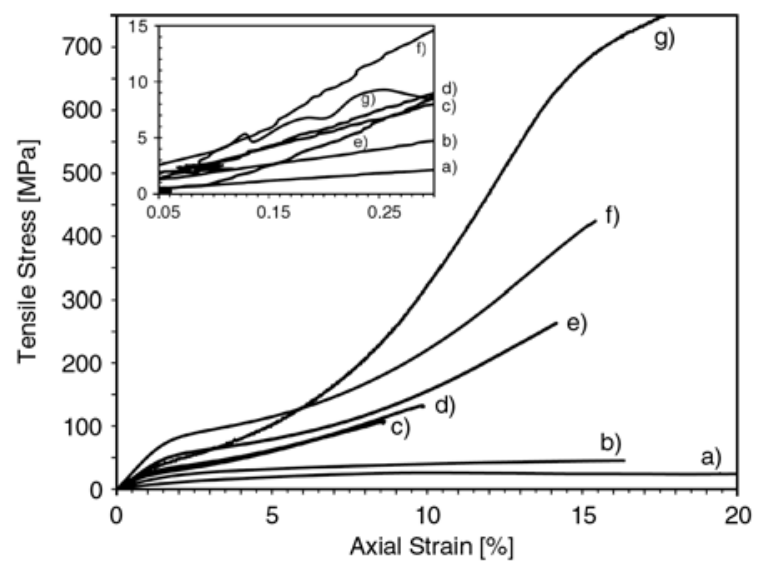

Figure 3. Stress-strain curves and their enlarged sections in the axial strain interval between 0,05 and $0,25 \%$ (insertion) of: a) 14 days PA 6 matrix, b) 1 day PA 6 matrix, c) 14 day PA 6-SPC without catalyst, d) 14 day PA 6-SPC with catalyst, e) 1 day PA 6-SPC without catalyst, f) 1 day PA 6SPC with catalyst, and g) PA 6 yarn

chemical bonds between the matrix and the reinforcement and therefore, to reach the ideal case of interfacial adhesion.

Coming back to the tensile testing experiments, Figure 3, it should be noted that the starting materials behave quite differently. While the matrix films, Figures $3 \mathrm{a}$ and $3 \mathrm{~b}$, show a ductile type of deformation behaviour, particularly the wet sample, Figure $3 \mathrm{a}$, the rest of the samples demonstrate somewhat brittle characteristics, Figures $3 \mathrm{~b}-3 \mathrm{~g}$.

Of particular importance in this respect is the failure behaviour of the tested SPCs. The photograph displayed in Figure 4 was taken from a sample after tensile testing. It is quite evident that the expected delamination, being typical for such materials, is missing and a brittle mode of failure is observed.

It is also interesting to have a closer look at the enlarged stress-strain curves for the strain range $0.05-0.25 \%$ plotted in Figure 3. A more detailed inspection of these curves shows that the curve for the commercial yarn, Figure $3 \mathrm{~g}$, differs from the others with respect of its shape and position. This deviation from the general behaviour of the stress-

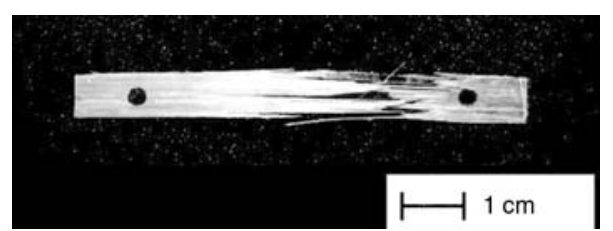

Figure 4. Photograph of a PA 6-SPC after tensile testing strain curves in this narrow strain interval could originate from the fact that the sample under testing represents a multifilament yarn, where all the filament do not experience the loading at the same time but, to some extent, subsequently. The stress-strain curves in the insertion were used for the evaluation of the $E$ modulus values, while the same curves in the larger strain range (0-20\%), gave the strength values. The obtained results are summarized in Table 1.

The PA 6 films have rather modest mechanical properties in contrast to those of PA 6 yarns. The yarns have an $E$ modulus value, which is 3-4 times higher, while the tensile strength $\left(\sigma_{u t s}\right)$ is even higher, Table 1 . The situation changes drastically when layered SPC is prepared - an improvement in the $E$ modulus of $200 \%$, and of the $\sigma_{u t s}$ values of $300-400 \%$ can be observed as compared to the starting isotropic film.

As expected, the application of transreaction catalyst shows quite impressive results: the improvement in $E$ modulus is $30 \%$ (for the dry samples) and $8 \%$ (for the wet samples) and for the ultimate tensile strength these values are 32 and $20 \%$, respectively, compared to the same samples without catalyst, Table 1. It is worth mentioning that the observation that the wet samples have in average two-fold lower mechanical properties as compared to the dry ones, Table 1 , is in a very good agreement with the findings of Hine and Ward for PA 66 [3].

\section{Conclusions}

It should be noted that the combination of the hot compaction approach along with film stacking represents a promising route for manufacturing single polymer composites with superior mechanical properties. The first results of catalyst application for improving the adhesion quality are also encouraging. Experiments for the optimisation of the described technique with the involvement of other polymer condensates are in progress.

\section{Acknowledgements}

The authors would like to thank the Foundation for Research Science and Technology New Zealand for their financial support (Grant No. UOAX 0406). 


\section{References}

[1] Capiati N. J., Porter R. S.: The concept of one polymer composites modeled with high density polyethylene. Journal of Materials Science, 10, 1671-1677 (1975). DOI: $10.1007 / \mathrm{BF} 00554928$

[2] Ward I. M., Hine P. J., Norris K.: Polymeric materials. British Patent GB 2253420, Great Britain (1992).

[3] Hine P. J., Ward I. M.: Hot compaction of woven nylon 6,6 multifilaments. Journal of Applied Polymer Science, 101, 991-997 (2006).

DOI: $10.1002 / a p p .22771$

[4] Yan R. J., Hine P. J., Ward I. M., Olley R. H., Bassett D. C.: The hot compaction of SPECTRA gel-spun polyethylene fibre. Journal of Materials Science, 32, 4821-4832 (1997). DOI: 10.1023/A:1018647401619

[5] Jordan N. D., Bassett D. C., Olley R. H., Hine P. J., Ward I. M.: The hot compaction behaviour of woven oriented polypropylene fibres and tapes. II. Morphology of cloths before and after compaction. Polymer, 44, 1133-1143 (2003). DOI: $10.1016 / \mathrm{S} 0032-3861(02) 00810-8$

[6] Hine P. J., Ward I. M.: Hot compaction of woven poly(ethylene terephthalate) multifilaments. Journal of Applied Polymer Science, 91, 2223-2233 (2004). DOI: 10.1002/app.13343

[7] Hine P. J., Astruc A., Ward I. M.: Hot compaction of polyethylene naphthalate. Journal of Applied Polymer Science, 93, 796-802 (2004). DOI: 10.1002/app.20517

[8] Ward I. M., Hine P. J.: The science and technology of hot compaction. Polymer, 45, 1413-1427 (2004). DOI: $10.1016 /$ j.polymer.2003.11.050

[9] Hine P. J., Olley R. H., Ward I. M.: The use of interleaved films for optimising the production and properties of hot compacted, self reinforced polymer composites. Composites Science and Technology, 68, 1413-1421 (2008). DOI: 10.1016/j.compscitech.2007.11.003

[10] Teishev A., Incardona S., Migliaresi C., Marom G.: Polyethylene fibers-polyethylene matrix composites: Preparation and physical properties. Journal of Applied Polymer Science, 50, 503-512 (1993). DOI: 10.1002/app.1993.070500314

[11] Marais C., Feillard P.: Manufacturing and mechanical characterization of unidirectional polyethylenefibre/polyethylene-matrix composites. Composites Science and Technology, 45, 247-254 (1992). DOI: 10.1016/0266-3538(92)90086-I

[12] Houshyar S., Shanks R. A., Hodzic A.: The effect of fiber concentration on mechanical and thermal properties of fiber-reinforced polypropylene composites. Journal of Applied Polymer Science, 96, 2260-2272 (2005).

DOI: 10.1002/app.20874
[13] Bárány T., Karger-Kocsis J., Czigány T.: Development and characterization of self-reinforced poly (propylene) composites: Carded mat reinforcement. Polymers for Advanced Technologies, 17, 818-824 (2006).

DOI: $10.1002 /$ pat.813

[14] Karger-Kocsis J.: Verbundwerkstoff aus Polypropylenverstärkung und Polypropylenmatrix sowie verschiedene Verfahren zu dessen Herstellung. German Patent DE 10237 803, Germany (2007).

[15] Thomas N. A., Singchin S., Karger-Kocsis J: Dynamic mechanical thermal analysis of all-PP composites based on $\beta$ and $\alpha$ polymorphic forms. Journal of Materials Science, 43, 3697-3703 (2008)

DOI: $10.1007 / \mathrm{s} 10853-008-2593-2$

[16] Banik K., Abraham T., Karger-Kocsis J.: Flexural creep behavior of unidirectional and cross-ply allpoly(propylene) (PURE ${ }^{\circledR}$ ) composites. Macromolecular Materials and Engineering, 292, 1280-1288 (2007).

DOI: $10.1002 /$ mame.200700180

[17] Hinrichsen G., Kreuzberger S., Pan Q., Rath M.: Production and characterization of UHMWPE fibers LDPE composites. Mechanics of Composite Materials, 32, 497-503 (1996). DOI: $\underline{10.1007 / \mathrm{BF} 02280631}$

[18] Lacroix F., Lu H-Q., Schulte K.: Wet powder impregnation for polyethylene composites: Preparation and mechanical properties. Composites Part A: Applied Science and Manufacturing, 30, 369-379 (1999). DOI: $10.1016 / \mathrm{S} 1359-835 X(98) 00085-2$

[19] Ogawa T., Mukai H., Osawa S.: Mechanical properties of ultrahigh-molecular-weight polyethylene fiberreinforced PE composites. Journal of Applied Polymer Science, 68, 1431-1439 (1998).

DOI: $10.1002 /(\mathrm{SICI}) 1097-4628(19980531) 68: 9$ $\leq 1431::$ AID-APP7>3.0.CO;2-C

[20] Fakirov S., Bhattacharyya D., Shields R. J.: Nanofibril reinforced composites from polymer blends. Colloids and Surfaces A: Physicochemical and Engineering Aspects, 313-314, 2-8 (2008).

DOI: 10.1016/j.colsurfa.2007.05.038

[21] Bhattacharyya D., Fakirov S.: Organoclay particulate, and nanofibril reinforced polymer-polymer composites: Manufacturing, modeling and application. in 'Nano- and micromechanics of polymer blends and composites' (eds.: Karger-Kocsis J., Fakirov S.) Hanser, Munich, 167-201 (2009).

[22] Duhovic M., Bhattacharyya D., Fakirov S.: All-PET nanofibrillar composites. Macromolecules, submitted (2009).

[23] Bhattacharyya D., Fakirov S.: Nano/microfibril reinforced single polymer composites: A novel concept. in ' 2 nd International Conforence on Multifunctional Materials \& Structures, Qingdao, China' accepted (2009). 
[24] Duhovic M., Maitrot P., Fakirov S.: Polyamide 66 polymorphic single-polymer composites. The Open Macromolecules Journal, in press (2009).

[25] Aharoni S. M.: n-Nylons: Their synthesis, structure and properties. Wiley, Chichester (1997).
[26] Fakirov S., Avramova N.: Applicability of GibbsThomson equation to nylon 6. Journal of Polymer Science Part C: Polymer Letters, 20, 635-641 (1982).

[27] Brandrup J., Immergut E. H., Grulke E. A.: Handbook of polymers. Wiley, New York (1999).

[28] Fakirov S. (ed.): Transreactions in condensation polymers. Wiley-VCH, Weinheim (1999). 